\title{
Ciência e políticas públicas nas cidades: revelações da pandemia da Covid-19 1
}

\author{
MARCOS SILVEIRA BUCKERIDGE I \\ e ARLINDO PHILIPPI JUNIOR II
}

\section{Introdução}

A PANDEMIA gerada pelo espalhamento do novo coronavírus tem como pano de fundo as cidades. É especialmente no ambiente urbano que a transmissão do vírus se dá e por isso a estrutura e o comportamento das cidades são fundamentais quando ocorre algum fenômeno extremo, como a pandemia do novo coronavírus. As cidades representam aglomerações, são locais de comércio intenso e de atividades culturais. É onde ocorre uma enorme quantidade de contatos pessoais. As cidades formam hubs de comunicação de onde partem e chegam membros das mais diversas populações de outras cidades do país e do mundo. Elas se tornam um ambiente propício para o espalhamento de doenças infecciosas. Portanto, é quase natural que o cenário urbano tenha sido fundamental em vários aspectos durante a pandemia de 2020.

Alguns dos principais indicadores da qualidade de resposta ao evento extremo de uma pandemia numa cidade são: 1) o cuidado com os contatos (isolamento social); 2) o uso do conhecimento científico para conduzir as ações; 3 ) o desenho de políticas públicas para controlar a expansão da doença; e 4) o provimento dos serviços que permitam cuidar de doentes e evitar mortes. Quanto melhores forem as performances locais nas cidades, menor será o número de mortes e menores serão os posteriores impactos socioeconômicos. Assim, a fisiologia urbana e a sua resiliência ao ataque de eventos extremos como a pandemia do novo coronavírus importam, e muito, para medir os efeitos finais sobre a população.

As resiliências das cidades à pandemia se tornam mais complexas e difíceis em regiões metropolitanas. Isso se deve especialmente à complexidade bem maior dessas regiões do que em cidades médias ou pequenas. Em regiões metropolitanas como São Paulo e Rio de Janeiro, por exemplo, são altos os níveis de desigualdade, um problema que está ligado às diferenças gritantes na estrutura urbana. Em São Paulo, há pelo menos oito padrões urbanos distintos (Nery et al., 2019), que coexistem praticamente em todos os seus distritos administrativos. Isso faz com que a desigualdade permeie a maioria das regiões, agravando as diferenças que tornam a cidade proporcionalmente mais vulnerável do que as que possuem padrões socioeconômicos mais uniformes. 
Neste trabalho, propomos inicialmente uma pequena teoria das cidades. Em seguida discutimos o mecanismo básico de geração de políticas públicas na sociedade, salientando o papel da ciência e das aspirações da população em contraste com a política e a gestão urbana, que são os setores que tomam as decisões e determinam os resultados finais. A geração de políticas públicas consequentes é o que define o comportamento de uma cidade diante de eventos extremos que ameacem a sua estabilidade. Por fim, examinamos o desempenho da capital paulista ante a pandemia do novo coronavírus, salientando as carências de conexões e deficiências nas políticas públicas e as suas implicações para a sustentabilidade urbana.

\section{A cidade como um sistema complexo}

A urbanização tem vantagens, fazendo que os custos para se viver sejam proporcionalmente menores do que em zonas rurais. Bettencourt et al. (2010) desenvolveram uma teoria científica das cidades, analisando-as através de sua escalabilidade. Eles descobriram que as regras que regem funcionamento, crescimento e escala das cidades são similares às que ocorrem nos seres vivos. Da mesma forma que quanto maior for um organismo, menos energia ele consumirá para manter suas células, as cidades, ao dobrarem de tamanho, têm seu consumo de energia reduzida em $15 \%$.

Em seu livro sobre a teoria das cidades, Geoffrey West (2018) mostrou que, devido a fenômenos de escala similares aos dos organismos vivos, ao dobrar o tamanho de uma cidade, os salários, índices de saúde, número de patentes, escolas, entre outros, aumentam entre $15 \%$ e $20 \%$. O mesmo ocorre com aspectos negativos: casos de doenças, taxa de criminalidade e a quantidade de resíduos produzida são também $15 \%$ a $20 \%$ maiores.

As cidades possuem algumas características importantes: 1) elas são sistemas complexos que funcionam em rede (Jardim; Buckeridge, 2020); 2) dependendo de seu tamanho e taxa de crescimento elas atraem mais e mais pessoas, pois exigem menor custo de vida e têm maior disponibilidade de produtos e serviços ( $15 \%-20 \%$ a mais devido ao fenômeno de escala); e 3 ) as cidades também intensificam, na mesma proporção, alguns problemas relevantes, como o impacto sobre o meio ambiente, a produção de resíduos, criminalidade e a proliferação de doenças.

Segundo o Departamento de Assuntos Econômicos e Sociais das Nações Unidas, ${ }^{2}$ a pressão por aumento na população urbana no mundo ocorre por dois fatores. Um deles é o aumento populacional geral no planeta, e o outro é o aumento na percentagem de áreas urbanas em todo planeta. Essas pressões agiram sobre o Brasil, produzindo um crescimento urbano muito forte em que a Região Metropolitana de São Paulo (RMSP) cresceu fortemente desde a segunda metade do século XX (Seade, 2014). Após esse período, grandes regiões metropolitanas como a RMSP já experimentam diminuição em sua taxa de crescimento por vários fatores, entre eles o envelhecimento da população e uma queda de fertilidade, que tem razões multifatoriais e ainda não são bem compreendidas. 
Considerando que as cidades são sistemas complexos que se comportam em rede. Jardim e Buckeridge (2020) examinaram os oito padrões urbanos (AH) propostos por Nery et al. (2019) para São Paulo e mostram que cada um dos padrões pode ser representado como uma rede hierárquica baseada em variáveis estruturais (dados do censo de 2010 somado a outros obtidos do metrô e da extinta Emplasa). O município de São Paulo foi subdividido em três subgrupos que salientaram desigualdades de diferentes tipos. Jardim e Buckeridge (2020) propõem que seja pouco provável que se resolvam problemas como a criminalidade ou a mobilidade urbana em uma grande cidade como São Paulo abordando o problema apenas a partir de um único ângulo. Assim, qualquer formulação de política pública que vise a resolução de problemas urbanos terá que ser considerada de um ponto de vista sistêmico.

\section{A diversidade dos problemas relacionados às cidades}

No mundo, fatores ligados à cultura, à economia e à disponibilidade de tecnologias, determinam tanto a velocidade como o modo de desenvolvimento de uma cidade. Assim, o presente traz a marca de sua história. As decisões tomadas ao longo de seu desenvolvimento e o sucesso relativo que tais decisões vão determinar a fluidez entre moradores, o que a cidade oferece para gerar bem-estar, trabalho e progresso. Considerando a forma de governo adotada no Brasil, o status atual de uma cidade como São Paulo depende de como seus governantes tomaram decisões com base em ideias, tecnologias e aspirações da população no passado e também os interesses políticos. Uma consequência desse processo é que as cidades originadas a partir de expansão urbana descontrolada e não planejada acabam pagando um alto preço por esse descontrole. Especialmente quando são atingidas por eventos extremos, como os impactos das mudanças climáticas (secas e chuvas intensas) e fenômenos como a pandemia do novo coronavírus.

\section{Fisiologia urbana}

As cidades possuem uma dinâmica análoga aos ecossistemas. Assim como esse último, o que denominaremos aqui como urbsistema consiste no fluxo de materiais através de um sistema urbano complexo e pleno de interações de diversos tipos. Cidades são, portanto, sistemas adaptativos complexos cuja dinâmica depende de interações em forma de redes para funcionar. Assim como o ecossistema, uma cidade necessita de elementos básicos, como água, energia e materiais, e esse processo gera continuamente resíduos.

Os urbsistemas são compostos por dois subsistemas, um primário e outro secundário. O Subsistema Urbano Primário tem como centro a própria cidade, que processa os materiais, consome energia e água e gera resíduos. Quanto maior o nível de sustentabilidade de um urbsistema, menor será a quantidade de resíduos produzida.

Os materiais que entram na cidade geralmente são produzidos no meio rural ou por indústrias nacionais e estrangeiras. Eles entram na cidade através 
de diferentes formas de transporte (rodoviário, fluvial, férreo, aéreo, marítimo etc.) e, na maioria das vezes, são armazenados antes de serem consumidos. Essa é a característica sistêmica básica das cidades e faz que ela possa ser modelada utilizando ferramentas como as propostas por Meadows (1985) e Jardim e Buckeridge (2020).

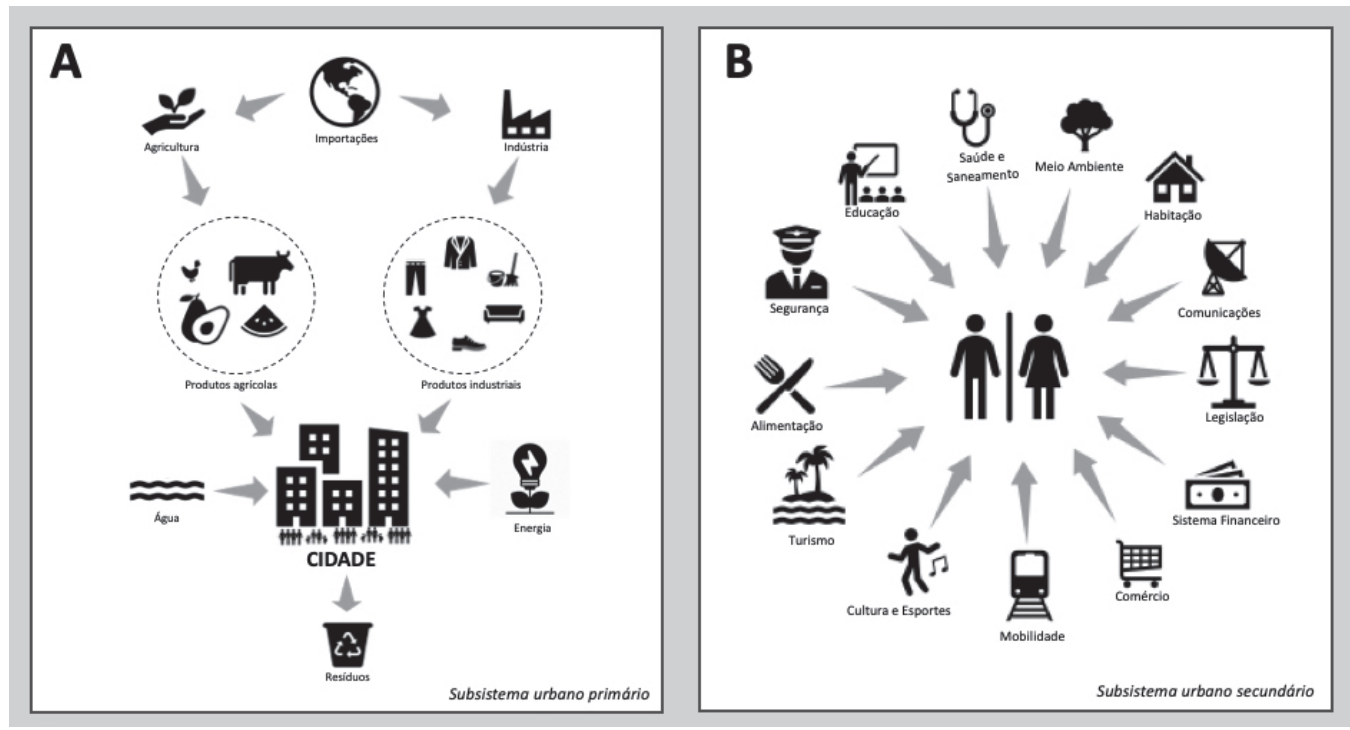

Fonte: Elaboração própria.

Figura 1 - Visão geral do urbsistema. Aqui são mostrados os elementos do Subsistema Urbano Primário (A) existente na maioria das cidades modernas. O urbsistema (análogo ao ecossistema) consiste em um fluxo de materiais, provenientes do setor agrícola, da indústria e de importações, que entram nas cidades e são processados com o uso de água e energia pelos processos do subsistema secundário (B). A interação em rede dos elementos do subsistema secundário gera resíduos (lixo e esgoto) que geralmente são retirados do meio urbano. Quanto menos água e energia forem usados e quanto menos resíduos forem produzidos, mais sustentável será a cidade.

Seres humanos, animais e plantas consomem os materiais que adentram a cidade. Eles a permeiam como habitantes ou como visitantes. Todo esse contingente de seres vivos (sem falar da biodiversidade residente nas cidades) requer especialmente fornecimento de água, energia e alimentos para sobreviver. Para que uma cidade seja minimamente estável, o Subsistema Urbano Primário precisa ser consistente. Ele precisa ser adaptativo e resiliente. Pode haver interrupção parcial e momentânea na entrada de materiais, água e energia. No entanto, uma interrupção prolongada pode gerar colapso, alterando completamente o equilíbrio do urbsistema. Quando algum evento extremo causa disrupção no Subsistema Urbano Primário, a cidade pode deixar de existir como tal. Um exemplo clássico disso é o dos astecas, na região do México. 
O Subsistema Urbano Secundário, onde uma série de serviços coexistem (Figura 1B), é totalmente dependente do Sistema Urbano Primário, sendo esse último essencial para que existam os serviços básicos aos habitantes de uma cidade.

A desigualdade tem estado presente nos dois subsistemas. Em São Paulo, o fornecimento desigual de água (Buckeridge; Ribeiro, 2018), bem como o de energia à população criam diferenças importantes no padrão de vida das pessoas. No Subsistema Urbano Secundário, são inúmeras as combinações de deficiências em diferentes regiões que determinam os padrões de desigualdade (Nery et al., 2019; Jardim; Buckeridge, 2020). Nesse subsistema, mecanismos basais que possibilitam a vida dos habitantes e visitantes são: educação, saúde, meio ambiente, comunicação, legislação, sistema financeiro, comércio, mobilidade, cultura e esportes, turismo e alimentação (Figura 1B). Várias outras redes geradoras de serviços podem ser adicionadas ao Subsistema Urbano Secundário. Porém, os que aqui são expostos são aqueles com maior hierarquia nas redes urbanas modernas. O bom nível de vida e a capacidade de reação (resiliência) de uma cidade a eventos extremos (mudanças climáticas e epidemias por exemplo) são diretamente proporcionais à qualidade do Subsistema Urbano Secundário. No caso da pandemia do novo coronavírus numa cidade como São Paulo, deveríamos esperar que a qualidade do Subsistema Urbano Secundário iria atenuar a profundidade do impacto e a gravidade das consequências socioeconômicas e políticas no período posterior ao evento. Porém, há um outro elemento essencial para determinar a capacidade de reação: as políticas públicas. Assim, antes de examinarmos como a cidade de São Paulo enfrentou a pandemia, vamos partir do princípio de que em conjunto, as características estruturais e as políticas públicas determinam o nível de performance do urbsistema.

\section{Mecanismo gerador de políticas públicas}

O Brasil neste momento fervilha com publicações intelectualmente consistentes sobre as políticas públicas e a gestão urbana (alguns exemplos: Leite, 2012; Caldas, 2018; Philippi Jr.; Bruna, 2019). Portanto, a ideia aqui não é fazer uma revisão de políticas públicas urbanas, mas oferecer um arcabouço sobre o qual se possa raciocinar de forma bem geral como a pandemia da Covid-19 vem interferindo na vida e negócios da capital paulista.

Diferentes grupos sociais usam suas abordagens de preferência para levantar questões e problemas urbanos. A sociedade em geral expressa um conjunto de aspirações, que emanam das opiniões de indivíduos, grupos, entidades e instituições. Grupos de interesse (associações, políticos, acadêmicos e outros) estudam, discutem e produzem visões críticas sobre problemas urbanos como deficiências na educação, segurança e saúde e outros elementos do Subsistema Urbano Secundário.

O reflexo das atividades desses grupos se dá especialmente por meio de artigos de especialistas e da mídia, que reverberam as opiniões coletivas, formando 
assim a opinião pública. Questões mais profundas e sofisticadas são levantadas pela arte através dos elementos da cultura. Já os cientistas geralmente usam a suas ferramentas próprias para formular projetos e tentar encontrar soluções para os problemas mais evidentes. Eles escolhem um problema, fazem compilações de dados, executam análises e tiram conclusões baseadas nestes dados.

Para que um problema urbano seja colocado na agenda de políticas públicas, é necessário um certo equilíbrio entre esses três elementos. Segundo John Kingdon (2007), a colocação de problemas nas agendas de políticas públicas depende da existência de uma "sopa primordial", onde problemas e soluções convivem e podem ser ou não selecionados darwinianamente para serem resolvidos.

Esse processo seletivo depende da formação de janelas de oportunidades. Essas janelas podem ser atribuídas a fatores favoráveis como a existência de estudos bem feitos sobre o assunto, baixo custo de implantação, lobby por grupos de interesse e da situação política favorável. Momentos pré-eleição são propícios para a inclusão de itens nas agendas dos tomadores de decisão. Cabe ressaltar que inovações disruptivas nas políticas públicas são raras, sendo geralmente o resultado de ideias, dados e opiniões que já existiam no sistema.

Forma-se assim, na sociedade, um espaço de ideias (representado no triângulo da Figura 2) que reflete as diferentes camadas da sociedade, cada uma com sua visão e tendo diferentes graus de influência sobre a agenda pública. Nesse espaço de ideias (pontos vermelhos dentro do triângulo), problemas e soluções flutuam como se fossem moléculas em um gás onde ocorrem "choques" numa analogia com as reações químicas. Nesse espaço, problemas e soluções que carregam mais informação têm maior probabilidade de "atrair" um choque. Quando um desses choques ocorre, forma-se um contexto favorável (uma janela de oportunidade) para que haja inserção na lista de prioridades de políticas públicas dos tomadores de decisão. Para isso, é preciso haver reverberação na comunidade política e de gestão pública, que poderão ou não implementar políticas públicas no sentido de aproveitar a sincronicidade no espaço de ideias.

O sucesso de uma política pública depende de sua própria concepção. Se, por exemplo, uma política pública é concebida por atribuição unitária - ou seja, por acreditar que um problema complexo pode ser resolvido através de ações específicas sobre algumas de suas causas - ao invés de usar um ponto de vista sistêmico e cientificamente embasado - as soluções podem se apresentar como carentes do "choque" e na maioria dos casos são fadadas ao fracasso. 


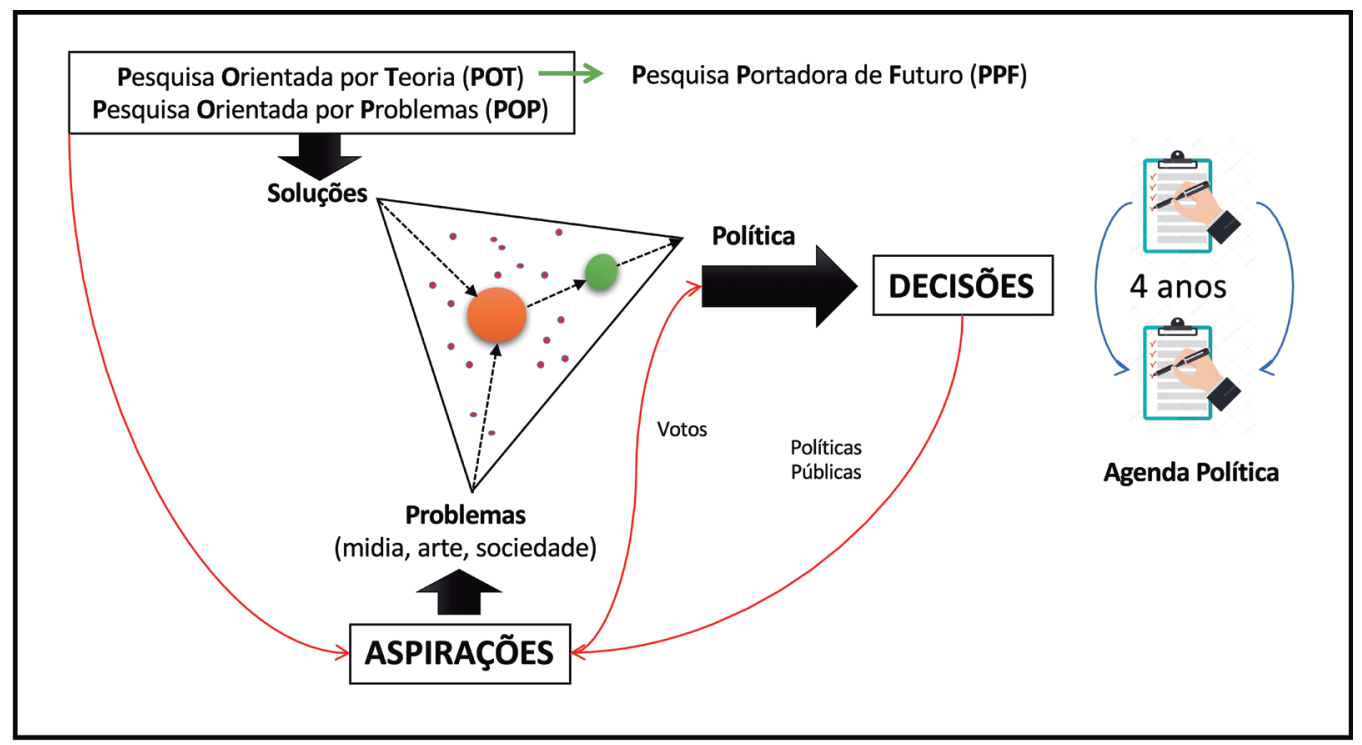

Fonte: Elaboração própria.

Figura 2 - Representação do mecanismo principal de geração de políticas públicas. A ciência funciona como o principal produtor de soluções enquanto as aspirações da sociedade apontam os problemas. Dentro do triângulo coexistem problemas e soluções (pequenos círculos rosados) em uma "sopa primordial” (interior do triângulo). O choque entre uma solução e um problema complementar (círculo laranja) pode gerar um item (verde) na agenda de políticos. Se incorporado à agenda de quatro anos da política, o item de agenda poderá acabar sendo executado pela gestão pública. Baseado em algumas das ideias de Kingdon (2007).

Um dos vértices do triângulo apresentado na Figura 2 representa a ciência. Para efeito didático a ciência aqui é representada de três formas: 1) Pesquisa Orientada por Teoria (POT); 2) Pesquisa com Potencial de Futuro (PPF) e 3) Pesquisa Orientada por Problemas (POP). Os três tipos de pesquisa são importantes para a geração de políticas públicas. A diferença está no tempo que leva até que a ideia se torne aplicável no âmbito de encontrar um problema que ela resolva dentro da "sopa primordial". Assim, a probabilidade é maior de que a ciência do tipo POP se torne geradora de políticas públicas consistentes. Mas é importante lembrar que as ciências do tipo POT e PPF são fundamentais, pois elas antecedem a pesquisa POP. Em outras palavras, POP não pode existir antes que a ciência POT e PPF sejam realizadas. É por isto que as sociedades que mantém pesquisa básica (POT e PPF) ativa e fazem boas conexões com a pesquisa aplicada (POP) são as que obtêm maior sucesso em suas políticas públicas.

$\mathrm{O}$ vértice das Aspirações refere-se ao conjunto de setores da sociedade que apontam constantemente as falhas e sugerem caminhos para que os subsistemas urbanos primários e secundários se tornem mais eficientes. A mídia, a arte, as organizações não governamentais (ONG) têm um papel crucial em produzir os 
elementos denominados "problemas" que flutuarão no universo de ideias da "sopa primordial". O interessante é que na maioria dos casos, os problemas são dimensionados com sugestões de possíveis soluções. Não raro encontrar ONG e mídia que já se adiantam e buscam no universo do conhecimento científico as bases para que determinados problemas sejam resolvidos. Quando isto acontece, o choque apresenta maior maturidade - com referência à complementaridade entre problema e solução - aumentando a probabilidade de que uma política publica derivada desta ideia funcione na prática.

Assim, se for possível aumentar a consciência da sociedade sobre os três vértices do triângulo que representam o espaço de ideias que geram as políticas públicas, possivelmente intensificaríamos o número de "choques" entre problemas e soluções, aumentando assim a aplicabilidade e o sucesso das políticas publicas. Em outras palavras, esse tipo de política pública é uma propriedade emergente dos choques entre problemas e soluções no espaço urbano que compreende os Subsistemas Urbanos Primários, Secundários e de outros níveis mais específicos.

Essas ideias não visam um controle estrito das aspirações da sociedade, das ideias dos cientistas ou dos políticos, mas, como dito acima, de induzir à conscientização da população urbana a respeito da importância dos três elementos (ciência, aspirações e política) de tal forma a maximizar a probabilidade de que "choques" produtivos ocorram.

O mecanismo de interação entre ideias e problemas que deriva da "sopa primordial" de nosso triângulo pode ser visto como o gerador de itens na agenda da política e da gestão pública. Se políticos e gestores levarem em consideração o grau de maturidade dos itens de suas agendas no que concerne aos choques geradores de problemas com soluções já engendradas pela ciência, tal item de agenda de uma cidade poderá passar para a fase democrática de discussão e votação pela câmara de vereadores e em seguida para a esfera da gestão para que haja implementação.

Considerando que os mandatos na política são de quatro anos, uma agenda que contenha itens com maior probabilidade de funcionar - uma vez que já têm embasamento científico e discussões prévias com a sociedade - aceleraria os processos de mudança e aumentaria a eficiência do sistema gerador de políticas públicas. É importante salientar aqui que há itens na agenda da política e da gestão pública que precisam transcender o período da política democrática atual (quatro anos), uma vez que a implantação de algumas políticas pode levar décadas. Provavelmente esse será o caso da resolução dos problemas relacionados à desigualdade nas cidades brasileiras, por tratar-se de um problema complexo e que exige soluções de longo prazo. Está aí a distinção do estadismo nos líderes públicos. Compreender a transcendência de itens de agendas de políticas públicas é fundamental para que uma população realmente se beneficie das decisões públicas de seus governantes. 
É importante salientar ainda que há uma interação direta entre o mecanismo gerador de políticas públicas descrito e a qualidade de funcionamento dos Subsistemas Urbanos Primário e Secundário descritos acima. Quanto mais sólidas as propostas de políticas públicas colocadas nas agendas dos diversos vereadores e maior a aceitação de implantar tais ideias pela prefeitura e suas secretarias, mais eficiente e sustentável se tornará o urbsistema como um todo.

Como acontece na ecologia, a performance do urbsistema (análogo ao ecossistema) é sistêmica e, portanto, interconectada através de redes com elementos que se conectam em diferentes níveis. Um exemplo desse tipo de funcionamento foi colocado por Jardim e Buckeridge (2020 - neste volume ). Nele algumas das redes de São Paulo foram comparadas conforme os oito padrões urbanos descritos por Nery et al. (2019). A aplicação da análise de redes complexas sobre esses dados, ante a pandemia, demonstrou a fragilidade da cidade de São Paulo como um resultado dos altos níveis de desigualdade hoje existentes.

Em suma, quanto maior o nível sistêmico de uma política pública urbana e quanto maior for a base de dados que a suporta, maior seria a probabilidade de que esta tenha sucesso após a sua implantação. O uso de políticas públicas sistêmicas favorece a sustentabilidade, ajudando a cumprir metas que levem uma cidade cada vez mais perto de atingir os objetivos do desenvolvimento sustentável.

\section{A pandemia e a cidade}

Entre as deficiências no lidar com a pandemia na cidade de São Paulo podem-se apontar falhas que aconteceram durante o desenrolar do espalhamento da doença e também falhas relacionadas às decisões tomadas no passado.

A pandemia da Covid-19 (do inglês COronaVIrus Disease-19) expôs virtudes e defeitos da sociedade brasileira contemporânea. Uma parte da comunidade científica presente nas universidades e institutos de pesquisa se movimentou rapidamente, desviando a atenção para problemas relacionados ao novo coronavírus, seu modo de infecção e nas análises sobre o avanço da doença no Brasil e no mundo. Agências financiadoras como $\mathrm{CNPq}$ e Fapesp reagiram rápido, lançando programas para financiar projetos sobre aspectos da pandemia da Covid-19.

Esse episódio ilustra o valor que têm as instituições científicas brasileiras. Isso ocorreu porque as decisões do passado foram acertadas. O Brasil se empenhou em desenvolver uma ciência nacional forte nos últimos 40 anos, galgando inclusive um posto alto no ranking mundial de publicações e citações científicas.

Porém, durante a pandemia os governos aproveitaram relativamente pouco da ciência nacional. Nos âmbitos dos governos federal, estaduais e municipais, a maioria se exasperou em trabalhar com equipes relativamente pequenas e sequer conseguiram compilar os dados científicos e disponibilizá-los adequadamente para que a comunidade científica brasileira pudesse ajudar nas análises.

Praticamente o único objetivo perseguido pelos governos foi o de evitar sobrecarga do sistema de saúde, de forma a evitar mortes. Para isso, a abordagem dos governos de estados e municípios brasileiros se concentrou em uma 
das mais simples medidas para evitar o espalhamento de um vírus: o isolamento social. Intuitiva e matematicamente, o isolamento social é uma medida acertada (Prem et al., 2020). A ideia é que ele evitaria que os níveis de infecção aumentassem muito e com isso o número de internações e mortes deveria ser menor. No entanto, uma análise dos diferentes níveis de infecção em 56 países (Buckeridge, 2020) revelou que países com diferentes estratégias de isolamento apresentaram níveis similares de infecção por 100 mil habitantes e que há outros fatores que precisariam ser considerados.

A razão para isso é que a explicação do processo não é tão simples. A carência de múltiplas visões provenientes de um grande número de cientistas de diversas áreas do conhecimento acabou atrasando a visualização de padrões importantes que poderiam ter diminuído o impacto da pandemia sobre as áreas menos favorecidas das cidades (Jardim; Buckeridge, 2020), em particular do município de São Paulo que foi o epicentro da pandemia no Brasil. A não liberação de dados geoespacializados de casos e óbitos durante o período mais importante da pandemia (primeiros três meses) e o desmantelamento de instituições como a Emplasa, por exemplo, foram fatores preponderantes a contribuir com a carência de análises científicas que poderiam ter alterado significativamente a história da pandemia em São Paulo e no Brasil (Pereira, 2020).

Quanto aos problemas históricos, pode-se apontar a desigualdade socioeconômica crônica que a capital paulista possui. Esse é um problema que se correlaciona com décadas de processos decisórios que, de alguma forma, não levaram em consideração desenvolver uma estrutura urbana capaz de prover os serviços relacionados ao Sistema Urbano Secundário de forma equilibrada e sustentável. A cidade teve o seu crescimento mais acelerado quando atrelada ao desenvolvimento industrial paulista. Com isso abriu-se para a migração de pessoas de todo o país. Mas não criou ao mesmo tempo as condições de infraestrutura necessárias para acomodar os migrantes. A falta de políticas públicas nesse sentido acabou gerando um problema tão grande e complexo, como apontado por muitos autores, entre eles os recentes trabalhos de Nery et al., (2019) e Buckeridge et al. (2020), que para ser resolvido necessitará de ação sistêmica, com políticas múltiplas e paralelas, que possivelmente levarão décadas para serem completadas. De fato, há medidas sendo tomadas que estão tendo efeito (Leite et al., 2019), mas suas consequências se mostram lentamente e mantêm a cidade constantemente vulnerável aos efeitos de eventos extremos como ocorreu com a pandemia da Covid-19.

O efeito sistêmico da pandemia sobre São Paulo está exemplificado no artigo de Jardim e Buckeridge (2020), neste volume. Parece claro que a estrutura urbana, dada por elementos como mobilidade, criminalidade, saneamento, ambiente, habitação e populacionais, teve algum papel na dinâmica de espalhamento da Covid-19 no município paulista. No entanto, as análises feitas pelos autores foram atrasadas e seriamente prejudicadas pela falta de dados geoespa- 
cializados, que só se tornaram disponíveis em 17 de abril, quatro meses depois do início da pandemia. Isso revela que na maior cidade brasileira, que tem ao mesmo tempo a maior comunidade científica do Brasil, o mecanismo de geração de políticas públicas ainda apresenta pouca eficiência. Falta conexão maior entre a produção de conhecimento e a gestão pública. À luz do mecanismo explicitado na Figura 2, os dois vértices do triângulo refentes ao apontamento de problemas e à geração de soluções fizeram o seu papel, enquanto o vértice do triângulo responsável pela detecção de "choques" amadurecidos para a determinação de uma agenda de ação se limitou a uma fração limitada dos elementos existentes na sopa primordial existente em São Paulo. A lição aqui é que o vértice da política precisa melhorar. Ele precisa se conectar melhor com o restante da sociedade, olhando-a de uma forma ampla e levando em consideração o fato de que, quanto mais embasadas as políticas públicas estiverem em ciência, maior será o bem-estar da população.

\section{Como lidar com o urbsistema no período pós-Covid-19?}

A pandemia da Covid-19 ocorre em fases. No primeiro semestre de 2020 se passa a fase da chegada da doença e de seu espalhamento pela cidade de São Paulo, que se tornou o hub de distribuição do vírus para o país. O efeito sobre a capital paulista é de extrema relevância para o Brasil, já que se trata também do principal centro econômico e cultural do país. Portanto, as sequelas da passagem da pandemia pelo município e pela Região Metropolitana de São Paulo serão os principais vetores de transformação no período pós-Covid-19.

Eventos extremos, como a seca de 2014, ameaçaram fortemente a estabilidade do urbsistema paulistano (Buckeridge; Ribeiro, 2018). O ataque, nesse caso, foi sobre o Subsistema Urbano Primário, ameaçando um desligamento das redes do Subsistema Urbano Secundário, uma vez que sem água nenhum deles pode funcionar. Já na pandemia de Covid-19 em 2020, o ataque se deu especialmente sobre o Subsistema Urbano Secundário, uma vez que foi possível manter o subsistema primário funcional, com fornecimento de energia, água e de materiais. Havia uma possibilidade de ameaça ao subsistema primário através desse último fator (materiais), uma vez que a maioria dos países do mundo sofreu ataque similar e suas respectivas produções industriais diminuíram ou fecharam. A China conseguiu minimizar o impacto no país através da estratégia de lockdown da região de Wunan, enquanto essa mesma estratégia na Europa e sobre os Estados Unidos parecem não ter tido efeito forte o suficiente para evitar o ataque aos seus respectivos Subsistemas Urbanos Secundários.

Já o Subsistema Urbano Secundário de São Paulo poderá ter efeitos de diversas magnitudes. A Figura 3 representa o Subsistema Urbano Secundário paulistano com suas respectivas redes, como mostrado na Figura 1. Porém, nesse quadro apresentamos um panorama possível de como as redes dentro do subsistema secundário poderão reagir aos efeitos da passagem da pandemia de Covid-19 pela cidade. 


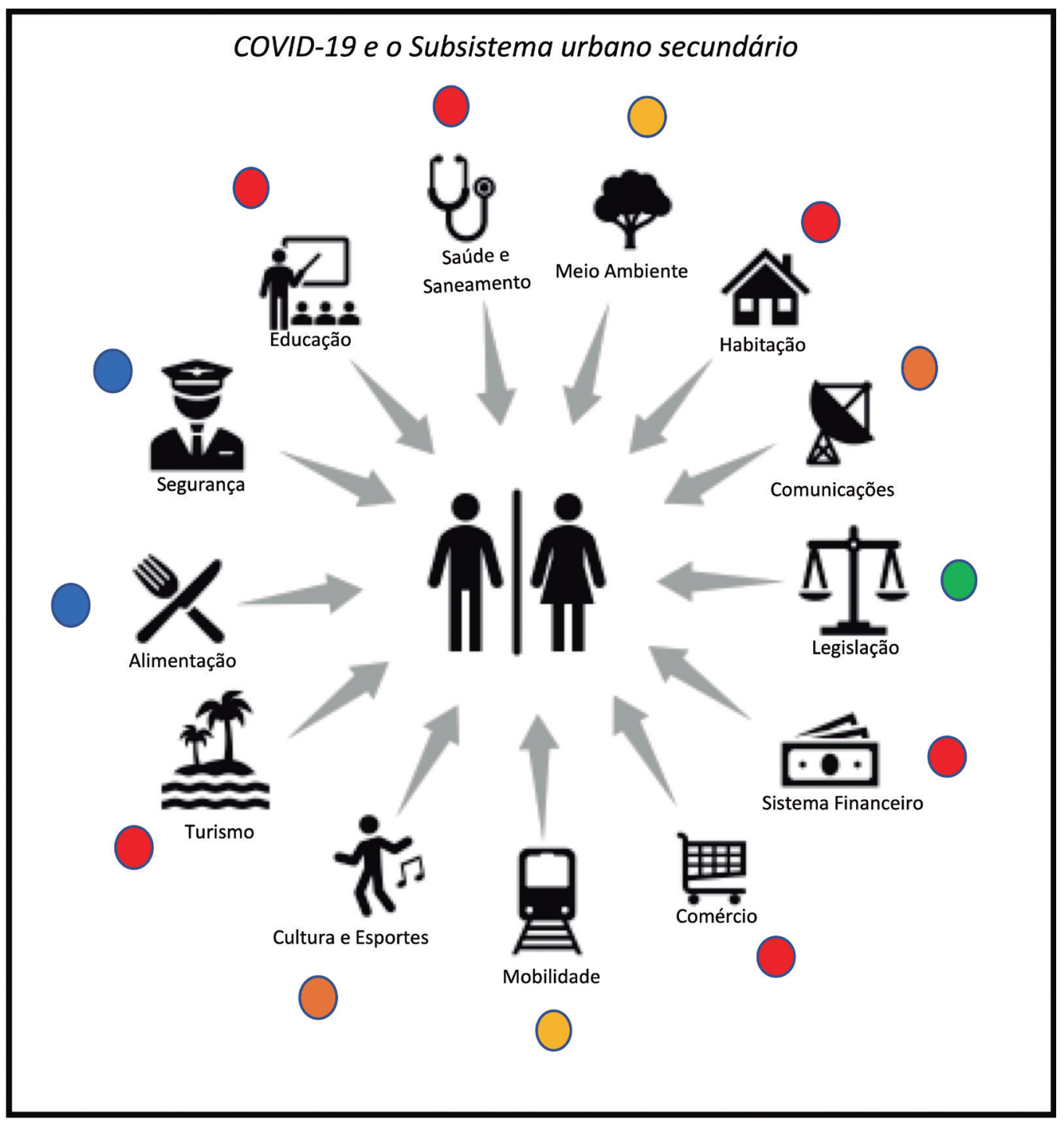

Fonte: Elaboração própria.

Figura 3 - Impactos da pandemia de Covid-19 sobre o Subsistema Urbano Secundário do urbsistema paulistano. As esferas coloridas representam visões arbitrárias das possíveis durações dos efeitos após o período inicial da pandemia. As cores seguem o código do espectro de cores com azul sendo o efeito menos duradouro e o vermelho os efeitos mais longevos.

Algumas das redes de serviços do subsistema urbano secundário deverão sofrer efeitos menos perenes, notadamente a Segurança e a Alimentação. Outros terão provavelmente algum feito mais alongado. Este é o caso da Cultura e Esportes e da Legislação que terão que sofrer adaptações. No caso de Cultura e dos Esportes, que têm em sua natureza as aglomerações de pessoas, não se sabe ainda quando haverá segurança para reiniciar. Isso provavelmente ocorrerá gradativamente e contribuirá com fortes efeitos sobre os Subsistemas Financei- 
ros e de Comércio, uma vez que empregos perdidos irão gerar múltiplos efeitos secundários. No caso da Mobilidade e do Meio Ambiente, esperam-se efeitos não tão duradouros. No primeiro caso, segundo um documento produzido pelo Programa USP-Cidades Globais do IEA-USP poderá haver um aumento da adoção do uso do carro individual, ${ }^{3}$ o que pode aumentar os congestionamentos e a poluição. Ao mesmo tempo, pode ser que o uso da bicicleta também seja mais intenso. No caso do meio ambiente, o mesmo documento aponta uma ansiedade maior da população por ocupar os espaços verdes urbanos. Isto demandará possivelmente transformações na forma de uso desses espaços, pelo menos enquanto não houver segurança sanitária em relação ao contágio pelo novo coronavírus. As comunicações foram bastante afetadas e isto tem reflexos múltiplos. O uso da internet foi essencial durante a pandemia e é possível que uma parcela significativa do uso deste tipo de comunicação, como ensino e reuniões e trabalho à distância usando comunicação digital, se torne permanente ou perdure por vários anos.

De longe, as redes mais afetadas do Subsistema Urbano Secundário pela pandemia serão Educação, Saúde, Turismo e subsistemas de comércio e financeiro. Exceto pela Saúde, que foi afetada diretamente pela pandemia, as demais redes foram atingidas em cheio pelos efeitos do isolamento social. O impedimento de trânsito das pessoas diminuiu drasticamente a atividade econômica, afetando diretamente o subsistema financeiro. Parte do comércio sofreu efeitos drásticos, com o fechamento de diversas lojas e empresas de serviços não essenciais. O Turismo talvez seja a rede mais atingida, uma vez que houve parada total em todo o mundo. Com o impedimento de viajar, empresas aéreas, hotéis e todas as empresas conectadas ao turismo foram tremendamente afetadas e grande parte fechou. A Educação continuou funcionando, mas através de uma transformação profunda na metodologia de ensino que, de uma hora para outra, teve que se adaptar à forma digital. Há aspectos positivos, mas para a maioria dos casos não há substituto, em educação, para as atividades presenciais.

A exposição acima é especulativa neste momento, pois faltam elementos que permitam prever o que pode acontecer, uma vez que ainda não se sabe quando uma vacina estará disponível. Teremos, portanto, que aguardar para ver a real extensão dos efeitos da pandemia sobre o Subsistema Urbano Secundário do município de São Paulo.

\section{Conclusões e perspectivas}

Numa analogia com a ecologia, a cidade pode ser vista como um urbsistema com uma estrutura primária e outra secundária, e essa última abriga a redes de serviços que determinam a qualidade de vida da cidade. A geração de políticas públicas é o principal mecanismo "fisiológico" pelo qual as cidades podem se tornar mais ou menos vulneráveis a eventos extremos, como as mudanças climáticas e as pandemias. 
A cidade de São Paulo apresenta uma série de vulnerabilidades. Uma delas está relacionada à desigualdade socioeconômica, que deriva de deficiências na produção e aplicação de políticas públicas no passado. As deficiências que mais se destacaram ante a pandemia da Covid-19 estão relacionadas às redes de serviços do Subsistema Urbano Secundário. Destacaram-se os efeitos mais drásticos e possivelmente mais duradouros sobre os setores de educação, saúde, sistema financeiro, comércio, turismo e habitação.

A pandemia da Covid-19 salienta a importância da sustentabilidade urbana. Mostra que a sustentabilidade só poderá ser atingida através de uma inteligência que considere sempre a aplicação de políticas públicas embasadas. Ainda há uma chance de que os tomadores de decisão prestem mais atenção ao que está na sopa primordial. Isso pode ser feito por meio de uma comunicação mais ampla com a comunidade científica. Tudo isso pode ser feito ao mesmo tempo em que as aspirações da sociedade - que seriam as de manter a saúde, saneamento, ter habitação, emprego e renda constantes, restabelecer os negócios, voltar às áreas verdes, voltar aos teatros, cinemas e aos estádios - sejam mantidas na mira de um plano de decisões com políticas públicas bem embasadas e que nos levem de volta à rota da sustentabilidade urbana.

\section{Notas}

l Os autores agradecem a valiosa contribuição de Audrey Buckeridge na leitura e nas sugestões e correções do manuscrito

2 United Nations. Department of Economic and social Affairs. Disponível em: <https:// www.un.org/en/development/desa/population/index.asps.

3 Pesquisa realizada pelo Programa USP-Cidades Globais do Instituto de Estudos Avançados da USP. Disponível em: <http://www.iea.usp.br/noticias/pesquisa-uso-espacos-publicos>.

\section{Referências}

BETTENCOURT, L. M. A. et al. Urban Scaling and Its Deviations: Revealing the Structure of Wealth, Innovation and Crime across Cities. PLoS ONE, v.5, n.11, p.el3541, 2010. doi:10.1371/journal.pone.0013541.

BUCKERIDGE, M. S. A abordagem brasileira para enfrentar a covid-10 é baseada em ciência? Ciência na Rua. 2020a. Disponível em: <https://ciencianarua.net/a-abordagem-brasileira-para-enfrentar-a-covid-19-e-baseada-em-ciencia/>.

Global analysis of the infection by Covid-19. Ambiente \& Sociedade (aceito para publicação em maio de 2020).

BUCKERIDGE, M. S.; RIBEIRO, W. C. Livro Branco da Água. A crise hídrica na região metropolitana de São Paulo em 2013-2015: Origens, Impactos e Soluções. Instituto de Estudos Avançados, 2018. 175p. Disponível em: <http://www.iea.usp.br/ publicacoes/ebooks/livro-branco-da-agua>. 
CALDAS, M. F. A utopia da reforma urbana: ação governamental e política pública no Brasil. Belo Horizonte: C/Arte, 2018

JARDIM, V. C.; BUCKERIDGE M. S. Análise sistêmica do município de São Paulo e suas implicações para o avanço dos casos de Covid-19. Estudos Avançados, v.34, n.99, 2020 .

KINGDON J. W. Agendas, Alternatives, and Public Policies. 2.ed. In: SARAVIA, E.; FERRAREZI, E. Politicas Públicas, 2007. Coletânea Volume 1. Como chega a hora de uma ideia (p.219-24) Juntando as coisas (p.225-46).

LEITE, C. Cidades sustentáveis, cidades inteligentes. São Paulo: Bookman, 2012.

LEITE, C. et al. Indicadores de desigualdade para financiamento urbano de cidades saudáveis. Estudos Avançados, v.33, n.97, p.37-60. 2019.

MEADOWS, D. H. Thinking in systems. London: Earthscan. 1985. Disponível em: <http://137.63.145.17:8787/xmlui/bitstream/handle/123456789/109/meadows.pdf? sequence $=1$ \& isAllowed $\mathrm{y}>$.

NERY, M. B.; SOUZA, A. A. L.; ADORNO, S. Os padrões urbano-demográficos da capital paulista. Estudos Avançados, v.33, n.97, p.7-36, 2019.

PEREIRA, J. A. G. Governo de SP demorou para criar sistema de monitoramento da Covid-19. Direto da Ciência. 2020. Disponível em: <http://www.diretodaciencia.com/2020/06/04/governo-de-sp-demorou-para-criar-sistema-de-monitoramento-da-covid-19/?utm_campaign=recomenda\&utm_medium=social\&utm_ source $=$ whatsapp $>$.

PHILIPPI JUNIOR, A.; BRUNA, G. C. Gestão urbana e sustentabilidade. Barueri: Manole, 2019.

PREM, K. et al. The effect of control strategies to reduce social mixing on outcomes of the COVID-19 epidemic in Wuhan, China: a modelling study. The Lancet, 2020. https://doi.org/10.1016/S2468-2667(20)30073-6.

SEADE - Fundação Sistema Estadual de Análise de Dados. Perspectivas demográficas dos distritos do Município de São Paulo: o rápido e diferenciado processo de envelhecimento. SP Demográfico, v.14, n.1, p.1-17, 2014.

WEST, G. Scale: the universal laws of life, growth, death in organisms, cities and companies. London: Penguin Books, 2018. 496p.

RESUMO - A pandemia da Covid-19 revelou virtudes e deficiências da cidade de São Paulo no enfrentamento de um dos mais fortes eventos extremos do século XXI. Por um lado, a robustez da ciência paulista ajudou a enfrentar a pandemia, aconselhando sobre as questões de saúde no front da doença. Por outro, as deficiências nas políticas públicas do passado cobraram seu preço, revelando a face mais perversa da desigualdade existente na cidade, a vulnerabilidade a eventos extremos. Neste trabalho, descrevemos uma teoria das cidades, comparando o seu funcionamento ao de um ecossistema. Criamos o termo urbsistema que é composto de um Subsistema Urbano Primário e um Secundário. O primário coloca a cidade como a processadora de materiais e produtora de resíduos, usando para tanto, água e energia. O secundário é aquele que contém os 
principais serviços oferecidos pela cidade - educação, segurança, comunicação, transporte etc. As deficiências no funcionamento desses elementos caracterizam a desigualdade, uma vez que tais serviços são mais ou menos eficientes dependendo da região. Em seguida propomos um mecanismo de funcionamento da geração de políticas públicas, que é composto por três elementos: Ciência, Aspirações e Política. Colocados na forma de vértices de um triângulo, as soluções e problemas flutuam em uma "sopa primordial", gerando conjuntos problema-solução que podem ser adicionados às agendas da política e com isto constituírem políticas públicas que tenham maior probabilidade de acertar. Concluímos que os setores mais afetados serão educação, a saúde, o turismo e os subsistemas de comércio e financeiro.

Palavras-Chave: Covid-19, Ciência, Políticas públicas, São Paulo, Teoria das cidades.

ABSTRACT-The covid-19 pandemic revealed the virtues and deficiencies of the city of São Paulo in facing one of the most extreme events of the $21^{\text {st }}$ century. On the one hand, the robustness of science in São Paulo helped to face the pandemic, advising on health issues on the disease front. On the other hand, deficiencies in past public policies took their toll, revealing the most perverse face of inequality in the city, its vulnerability to extreme events. In this work, we describe a theory of cities, comparing their functioning to that of an ecosystem. We created the term urbsystem, comprising a Primary and a Secondary Urban Subsystem. The primary, analogous to that of an ecosystem, places the city as a processor of materials and a producer of waste, using water and energy for both activities. The Secondary Urban System contains the main services offered by the city - education, security, communication, transportation etc. The deficiencies in the functioning of these elements characterize inequality, since their efficiency varies depending on the region. We then propose a mechanism to operate the generation of public policies consisting of three elements: Science, Aspirations and Politics. Arranged in the form of the vertices of a triangle, solutions and problems float in a "primordial soup", generating sets of problems-solutions that can be added to political agendas and thus generate public policies that are more likely to be right. In the light of these ideas, we point out that one of the main deficiencies revealed during the pandemic was the lack of connection between the vertices of Science and Aspirations, and the vertex of Politics. We conclude that the most affected sectors will be education, healthcare, tourism and the subsystems of commerce and finance.

KEYWORDs: Covid-19, Science, Public policies, São Paulo, Theory of cities.

Marcos Silveira Buckeridge é professor titular do Instituto de Biociências e coordenador do Programa USP-Cidades Globais do Instituto de Estudos Avançados da Universidade de São Paulo. @ - msbuck@usp.br / http://orcid.org/0000-0002-5455-8136.

Arlindo Philippi Jr. é professor titular da Faculdade de Saúde Pública e vice-coordenador do Programa USP-Cidades Globais do Instituto de Estudos Avançados da Universidade de São Paulo. @ - aphij@usp.br / https://orcid.org/0000-0003-0420-7749.

Recebido em 18.6.2020 e aceito em 30.6.2020.

I Instituto de Biociências, Universidade de São Paulo, São Paulo, Brasil.

II Faculdade de Saúde Pública, Universidade de São Paulo, São Paulo, Brasil. 